\title{
Atomic-Level Investigation of $\mathrm{CH}_{x}$ and $\mathrm{C}_{2} \mathrm{H}_{x}$ Adsorption on $\beta$-SiC (111) Surface for CVD Diamond Growth from DFT Calculations
}

\author{
Naichao Chen and Fanghong Sun \\ School of Mechanical Engineering, Shanghai Jiao Tong University, Shanghai 200240, China \\ Correspondence should be addressed to Fanghong Sun, sunfanghong@sjtu.edu.cn
}

Received 30 April 2010; Accepted 28 June 2010

Academic Editor: Bo Zou

Copyright () 2011 N. Chen and F. Sun. This is an open access article distributed under the Creative Commons Attribution License, which permits unrestricted use, distribution, and reproduction in any medium, provided the original work is properly cited.

The focus of this paper is on the adsorption of unsaturated hydrocarbon molecules on $\beta$-SiC (111) surfaces during diamond film growth. The $\mathrm{CH}_{x}$ and $\mathrm{C}_{2} \mathrm{H}_{x}$ molecules have been investigated to obtain a specific insight into absorbing diamond processes on the atomic scale. Structural and electronic properties of $\mathrm{CH}_{x}$ and $\mathrm{C}_{2} \mathrm{H}_{x}$ adsorption on the Si- and C-terminated surfaces have been studied by first-principles calculations based on density functional theory (DFT). From the calculated energetics and geometries, we find that $\mathrm{C}_{2} \mathrm{H}_{x}$ adsorption on the Si-terminated surfaces has six possible surface reconstructions. For the C-terminated surface, there exist eight possible surface reconstructions. Five surface reconstructions, including $\mathrm{CH}_{2}$ adsorption on the Si- and Cterminated surface, $\mathrm{CH}-\mathrm{CH}_{2}$ and $\mathrm{CH}=\mathrm{CH}_{2}$ adsorption on the $\mathrm{C}$-terminated surface, and $\mathrm{C}_{2} \mathrm{H}_{5}$ adsorption on the Si-terminated surface, have the largest hydrogen adsorption energies and more stability of surface reconstructions. Calculations demonstrate that the Si-terminated surface is energetically more favorable for fabricating CVD diamond coatings than the C-terminated surface.

\section{Introduction}

A variety of chemical vapor deposition (CVD) techniques are able to deposit diamond films [1-3]. The intrinsic reactivity of a hetero-substrate under CVD plasma strongly determines the mechanisms competing with diamond nucleation. These mechanisms have often detrimental consequences on the quality of the interface with diamond $[4,5]$. The chemical kinetic model of CVD has been developed to study the detailed descriptions of both gas-phase and surface processes occurring in gas-activated deposition of diamond film [2, $3,6]$. Several reaction pathways describing deposition of diamond initiated by different gaseous species, including the $\mathrm{CH}_{3}, \mathrm{C}_{2} \mathrm{H}_{2}, \mathrm{C}$ [3], and several $\mathrm{C}_{2} \mathrm{H}_{\mathrm{x}}$ [6] species, have provided a specific insight into chemical processes. These techniques are capable of identifying the activation of the growing surface. In addition, the theoretical model has been employed to investigate diamond formation by combining mass, momentum, and energy balance equations for the gas flow with detailed chemical mechanisms for the gas phase and surface chemistry $[2,7]$. The gas phase composition profile and surface chemical kinetics for diamond formation have been solved. However, these types of issues do not well and enough describe the growth mechanism of diamond film and the acquiring diamond film of high quality efficiently. The surface diffusion [1] and quantum-mechanical calculations and localized kinetic analysis [8] farther highlight an understanding of the atomic-scale dynamics that lead to the CVD of diamond formation.

Recently, the CVD diamond coatings on SiC substrates have been investigated $[5,9,10]$. The formation of carbon phase and the roughening of the $3 \mathrm{C}-\mathrm{SiC}$ surface have been observed [4]. Therefore, adsorption of unsaturated hydrocarbon molecules on $\mathrm{SiC}$ surfaces is of great importance to investigate the initial-stage growth of diamond film on $\mathrm{SiC}$ substrates. At the same time, the $\mathrm{SiC}$ surface and its reconstructions have attracted much attention both in experiment [11] and theory [12] due to its fundamental interest and technological importance in recent years. Progresses in several theoretical applications, such as ab initio $[13,14]$ and empirical molecular dynamic $[15,16]$, have provided more specific insight into absorbing processes on the atomic scale. The surface relaxation and reconstructing behaviors have been derived from these calculations. The chemisorption of $\mathrm{C}_{2} \mathrm{H}_{2}$ and $\mathrm{CH}_{3}$ molecules onto the silicon carbide terminated $(2 \times 1)$ surface suggests that optimal $\mathrm{C}_{2} \mathrm{H}_{2}$ 
chemisorption has been found to occur with the adsorbate molecule situated above the cave site, while optimal $\mathrm{CH}_{3}$ chemisorption has been observed to present with the $\mathrm{CH}_{3}$ radicals bonding directly to the surface dangling bonds [17]. Structural and electronic properties of acetylene and ethylene adsorbed on $\beta$-SiC (001) surface with dimer site have been investigated based on density functional theory [18, 19]. However, the mechanism underlying diamond deposition $[1,6]$ has suggested that the carbon-carbon bond oriented in a direction parallel to the dimer site has not always occurred in the progress of the CVD diamond film growth. Up to now, the mechanisms of the CVD diamond formation on $\beta$-SiC surfaces have been seldom studied.

This state of the art has motivated the present study. The purpose of present work is to concentrate on the adsorption of hydrocarbons on the $\beta$-SiC (111) surface. Obviously, the growth species cannot be limited to only acetylene and ethylene in the process of CVD diamond film growth. In this paper, the $\mathrm{CH}_{x}$ and $\mathrm{C}_{2} \mathrm{H}_{x}$ adsorption on the $\beta$-SiC (111) surface has been studied by first-principles pseudopotential plane-wave method within the density functional theory (DFT). The geometry optimization has provided the surface relaxation and configuration. In addition, all the total energies of the surface reconstructions have been calculated to obtain structural properties. Thus, our computational results could promote the proper understanding on the growth mechanism of CVD diamond film on the $\beta$-SiC (111) surface.

\section{Theoretical Model}

Various complex prototypes occurred on the $\beta$-SiC (111) substrate surface are very hard to ascertain [20]. Therefore, the substrate surface in this work is assumed as the ideal $\beta$-SiC (111) structure in order to reduce the complexity. Although this study focused on these simple cases, the atomic-level investigation might be useful for understanding the real processors in the growth mechanism of CVD diamond film on the $\beta$-SiC (111) surface.

In order to account for per molecular adsorption on the $\beta$-SiC (111) substrate surface, the study is first made of determining the covalently bonds to $\mathrm{CH}_{x}$ and $\mathrm{C}_{2} \mathrm{H}_{x}$ gaseous species. The chemical reaction mechanism described by the chemical kinetics of diamond deposition [6] showed the conversion of $\mathrm{CH}_{x}$ and $\mathrm{C}_{2} \mathrm{H}_{x}$ gaseous species into the surface species. The models have been designed to be as many as possible. In this paper, all the structural and electronic properties of $\mathrm{CH}_{x}$ and $\mathrm{C}_{2} \mathrm{H}_{x}$ gaseous species adsorbed on the $\beta$-SiC (111) substrate surface have been studied. Namely, the $\mathrm{CH}_{x}$ gaseous species includes the $\mathrm{C}, \mathrm{CH}$ $\mathrm{CH}_{2}$, and $\mathrm{CH}_{3}$ molecules; the $\mathrm{C}_{2} \mathrm{H}_{\mathrm{x}}$ gaseous species includes the $\mathrm{C}_{2}, \mathrm{C}_{2} \mathrm{H}, \mathrm{C}_{2} \mathrm{H}_{2}, \mathrm{C}_{2} \mathrm{H}_{3}, \mathrm{C}_{2} \mathrm{H}_{4}$, and $\mathrm{C}_{2} \mathrm{H}_{5}$ molecules. The detailed analysis of making these models is presented in following parts.

Geometry optimizations, especially the movement of unsaturated hydrocarbon atoms, have been firstly studied to contribute to a fundamental understanding of surface reconstructions by the chemistry of hydrocarbons on the $\beta$-SiC (111) surfaces, which is of crucial technological importance.
TABLE 1: The surface reactions on the $\beta$-SiC (111) surface.

\begin{tabular}{lrrrr}
\hline & No.Si-terminated surface reactions & C-terminated surface reactions \\
\hline 1 & $\mathrm{Si}_{d(s)}+\mathrm{H}_{(\mathrm{g})}$ & $\leftrightarrow \mathrm{Si}_{d}-\mathrm{H}(s)$ & $\mathrm{C}_{d(s)}+\mathrm{H}_{(\mathrm{g})}$ & $\leftrightarrow \mathrm{C}_{d}-\mathrm{H}(s)$ \\
2 & $\mathrm{Si}_{d(s)}+\mathrm{C}_{(\mathrm{g})}$ & $\leftrightarrow \mathrm{Si}_{d}-\mathrm{C}(s)$ & $\mathrm{C}_{d(s)}+\mathrm{C}_{(\mathrm{g})}$ & $\leftrightarrow \mathrm{C}_{d}-\mathrm{C}(s)$ \\
3 & $\mathrm{Si}_{d(s)}+\mathrm{CH}_{(\mathrm{g})}$ & $\leftrightarrow \mathrm{Si}_{d}-\mathrm{CH}(s)$ & $\mathrm{C}_{d(s)}+\mathrm{CH}_{(\mathrm{g})}$ & $\leftrightarrow \mathrm{C}_{d}-\mathrm{CH}(s)$ \\
4 & $\mathrm{Si}_{d(s)}+\mathrm{CH}_{2(\mathrm{~g})}$ & $\leftrightarrow \mathrm{Si}_{d}-\mathrm{CH}_{2}(s)$ & $\mathrm{C}_{d(s)}+\mathrm{CH}_{2(\mathrm{~g})}$ & $\leftrightarrow \mathrm{C}_{d}-\mathrm{CH}_{2(s)}$ \\
5 & $\mathrm{Si}_{d(s)}+\mathrm{CH}_{3(\mathrm{~g})}$ & $\leftrightarrow \mathrm{Si}_{d}-\mathrm{CH}_{3}(s)$ & $\mathrm{C}_{d(s)}+\mathrm{CH}_{3(\mathrm{~g})}$ & $\leftrightarrow \mathrm{C}_{d}-\mathrm{CH}_{3(s)}$ \\
6 & $\mathrm{Si}_{d(s)}+\mathrm{C}_{2(\mathrm{~g})}$ & $\leftrightarrow \mathrm{Si}_{d}-\mathrm{C}_{2}(s)$ & $\mathrm{C}_{d(s)}+\mathrm{C}_{2(\mathrm{~g})}$ & $\leftrightarrow \mathrm{C}_{d}-\mathrm{C}_{2}(s)$ \\
7 & $\mathrm{Si}_{d(s)}+\mathrm{C}_{2} \mathrm{H}_{(\mathrm{g})}$ & $\leftrightarrow \mathrm{Si}_{d}-\mathrm{C}_{2} \mathrm{H}(s)$ & $\mathrm{C}_{d(s)}+\mathrm{C}_{2} \mathrm{H}_{(\mathrm{g})}$ & $\leftrightarrow \mathrm{C}_{d}-\mathrm{C}_{2} \mathrm{H}(s)$ \\
8 & $\mathrm{Si}_{d(s)}+\mathrm{C}_{2} \mathrm{H}_{2(\mathrm{~g})}$ & $\leftrightarrow \mathrm{Si}_{d}-\mathrm{C}_{2} \mathrm{H}_{2}(s)$ & $\mathrm{C}_{d(s)}+\mathrm{C}_{2} \mathrm{H}_{2(\mathrm{~g})}$ & $\leftrightarrow \mathrm{C}_{d}-\mathrm{C}_{2} \mathrm{H}_{2}(s)$ \\
9 & $\mathrm{Si}_{d(s)}+\mathrm{C}_{2} \mathrm{H}_{3(\mathrm{~g})}$ & $\leftrightarrow \mathrm{Si}_{d}-\mathrm{C}_{2} \mathrm{H}_{3}(s)$ & $\mathrm{C}_{d(s)}+\mathrm{C}_{2} \mathrm{H}_{3(\mathrm{~g})}$ & $\leftrightarrow \mathrm{C}_{d}-\mathrm{C}_{2} \mathrm{H}_{3}(s)$ \\
10 & $\mathrm{Si}_{d(s)}+\mathrm{C}_{2} \mathrm{H}_{4(\mathrm{~g})}$ & $\leftrightarrow \mathrm{Si}_{d}-\mathrm{C}_{2} \mathrm{H}_{4}(s)$ & $\mathrm{C}_{d(s)}+\mathrm{C}_{2} \mathrm{H}_{4(\mathrm{~g})}$ & $\leftrightarrow \mathrm{C}_{d}-\mathrm{C}_{2} \mathrm{H}_{4}(s)$ \\
11 & $\mathrm{Si}_{d(s)}+\mathrm{C}_{2} \mathrm{H}_{5(\mathrm{~g})}$ & $\leftrightarrow \mathrm{Si}_{d}-\mathrm{C}_{2} \mathrm{H}_{5}(s)$ & $\mathrm{C}_{d(s)}+\mathrm{C}_{2} \mathrm{H}_{5(\mathrm{~g})}$ & $\leftrightarrow \mathrm{C}_{d}-\mathrm{C}_{2} \mathrm{H}_{5}(s)$ \\
\hline
\end{tabular}

TABLE 2: The nomenclature of the structures of $\mathrm{C}_{2} \mathrm{H}_{x}$ adsorption.

\begin{tabular}{|c|c|c|}
\hline \multirow{2}{*}{ Name used } & \multicolumn{2}{|c|}{ Structure } \\
\hline & Si-terminated surface & C-terminated surface \\
\hline$X_{d}-\mathrm{C}_{2} \mathrm{H}(\mathrm{I})$ & $\mathrm{Si}_{d}-\mathrm{C}-\mathrm{CH}$ & $\mathrm{C}_{d}-\mathrm{C}-\mathrm{CH}$ \\
\hline$X_{d}-\mathrm{C}_{2} \mathrm{H}(\mathrm{II})$ & $\mathrm{Si}_{d}-\mathrm{CH}-\mathrm{C}$ & $\mathrm{C}_{d}-\mathrm{CH}-\mathrm{C}$ \\
\hline$X_{d}-\mathrm{C}_{2} \mathrm{H}_{2}(\mathrm{I})$ & $\mathrm{Si}_{d}-\mathrm{C}-\mathrm{CH}_{2}$ & $\mathrm{C}_{d}-\mathrm{C}-\mathrm{CH}_{2}$ \\
\hline$X_{d}-\mathrm{C}_{2} \mathrm{H}_{2}(\mathrm{II})$ & $\mathrm{Si}_{d}-\mathrm{CH}_{2}-\mathrm{C}$ & $\mathrm{C}_{d}-\mathrm{CH}_{2}-\mathrm{C}$ \\
\hline$X_{d}-\mathrm{C}_{2} \mathrm{H}_{2}(\mathrm{III})$ & $\mathrm{Si}_{d}-\mathrm{CH}-\mathrm{CH}$ & $\mathrm{C}_{d}-\mathrm{CH}-\mathrm{CH}$ \\
\hline$X_{d}-\mathrm{C}_{2} \mathrm{H}_{2}(\mathrm{IV})$ & $\mathrm{Si}_{d}-\mathrm{C}=\mathrm{CH}_{2}$ & $\mathrm{C}_{d}-\mathrm{C}=\mathrm{CH}_{2}$ \\
\hline$X_{d}-\mathrm{C}_{2} \mathrm{H}_{2}(\mathrm{~V})$ & $\mathrm{Si}_{d}-\mathrm{CH}=\mathrm{CH}$ & $\mathrm{C}_{d}-\mathrm{CH}=\mathrm{CH}$ \\
\hline$X_{d}-\mathrm{C}_{2} \mathrm{H}_{3}(\mathrm{I})$ & $\mathrm{Si}_{d}-\mathrm{C}-\mathrm{CH}_{3}$ & $\mathrm{C}_{d}-\mathrm{C}-\mathrm{CH}_{3}$ \\
\hline$X_{d}-\mathrm{C}_{2} \mathrm{H}_{3}(\mathrm{II})$ & $\mathrm{Si}_{d}-\mathrm{CH}-\mathrm{CH}_{2}$ & $\mathrm{C}_{d}-\mathrm{CH}-\mathrm{CH}_{2}$ \\
\hline$X_{d}-\mathrm{C}_{2} \mathrm{H}_{3}(\mathrm{III})$ & $\mathrm{Si}_{d}-\mathrm{CH}_{2}-\mathrm{CH}$ & $\mathrm{C}_{d}-\mathrm{CH}_{3}-\mathrm{CH}$ \\
\hline$X_{d}-\mathrm{C}_{2} \mathrm{H}_{3}(\mathrm{IV})$ & $\mathrm{Si}_{d}-\mathrm{CH}=\mathrm{CH}_{2}$ & $\mathrm{C}_{d}-\mathrm{CH}=\mathrm{CH}_{2}$ \\
\hline$X_{d}-\mathrm{C}_{2} \mathrm{H}_{4}(\mathrm{I})$ & $\mathrm{Si}_{d}-\mathrm{CH}-\mathrm{CH}_{3}$ & $\mathrm{C}_{d}-\mathrm{CH}-\mathrm{CH}_{3}$ \\
\hline$X_{d}-\mathrm{C}_{2} \mathrm{H}_{4}(\mathrm{II})$ & $\mathrm{Si}_{d}-\mathrm{CH}_{2}-\mathrm{CH}_{2}$ & $\mathrm{C}_{d}-\mathrm{CH}_{2}-\mathrm{CH}_{2}$ \\
\hline$X_{d}-\mathrm{C}_{2} \mathrm{H}_{5}$ & $\mathrm{Si}_{d}-\mathrm{CH}_{2}-\mathrm{CH}_{3}$ & $\mathrm{C}_{d}-\mathrm{CH}_{2}-\mathrm{CH}_{3}$ \\
\hline
\end{tabular}

The associated energy variation of the species adsorbed on the surface has terminally provided the structural and electronic reconstructions. It is well known that the most stable structure always has the minimum energy among the structures with atoms of the same element. In order to obtain the feasible surface reconstructions, the total energies of the $\mathrm{CH}_{x}$ and $\mathrm{C}_{2} \mathrm{H}_{x}$ adsorption on the $\beta$-SiC (111) surface have been calculated by DFT method. The two substrate surfaces [20], Si- and C-terminated surfaces, have been developed to investigate different $\mathrm{SiC}$ surfaces in this work. The associated chemical reaction model is provided in Table 1 .

The surface sites are defined as follows. " $X_{d}$ " represents a radical site; " $X_{d} R$ " represents an " $R$ " bonded to " $X_{d}$ " radical. " $X$ " denotes Si or $\mathrm{C}$ atom; " $R$ " denotes $\mathrm{CH}_{n}(n=$ $0,1,2,3)$ or $\mathrm{C}_{2} \mathrm{H}_{m}(m=0,1,2,3,4,5)$. The subscript $s$ in each chemical reactor represents the surface site, and $g$ means the vapor gas. In order to distinguish the $\mathrm{CH}_{\mathrm{x}}$ and $\mathrm{C}_{2} \mathrm{H}_{\mathrm{x}}$ adsorption on the $\mathrm{Si}$ - or C-terminated surface, the symbols are employed to represent the associated surface reconstructions. The nomenclatures are given in Table 2 . 
TABLE 3: The difference in total energy between $\mathrm{C}$ adsorption and the other $\mathrm{CH}_{x}$ adsorption on Si- and C-terminated surfaces.

\begin{tabular}{lcc}
\hline Species & Si-terminated surface $(\mathrm{eV})$ & C-terminated surface $(\mathrm{eV})$ \\
\hline $\mathrm{CH}$ & -17.9042 & -17.0661 \\
$\mathrm{CH}_{2}$ & -35.4609 & -34.5021 \\
$\mathrm{CH}_{3}$ & -52.3329 & -51.4378 \\
\hline
\end{tabular}

The calculations have been carried out by the DFT method which implemented in the simulation tool of $\mathrm{DMol}^{3}$ [21-23]. The surface has been modeled as a slab using only one $\beta$-SiC (111) unit cell for simplifying the structures and concentrating on the effectiveness of the $\mathrm{CH}_{x}$ and $\mathrm{C}_{2} \mathrm{H}_{x}$ adsorption on the $\beta$-SiC (111) surface. The slab consisted of two crystal lattices with four layers, and the bottom dangling bonds layers are saturated by hydrogen atoms. The slab is separated from the neighboring slab in the (111) direction by $10 \AA$ of vacuum thickness. The Monkhorst-Pack [24] scheme with $8 \times 8 \times 2 k$-point mesh has been employed for the Brillouin zone integration and geometry optimization.

\section{Results and Discussions}

The total energies of the surface reconstructions in this work refer to the energy of a specific arrangement of atoms based on the equations of quantum mechanics. The zero of energy is taken to be the infinite separation of all electrons and nuclei. Total energy is generally negative, corresponding to a bound state. In addition, total energy reflects the well-known fact that the most stable surface reconstruction only has the minimum total energy.

The total energies of all $\mathrm{CH}_{x}$ and $\mathrm{C}_{2} \mathrm{H}_{x}$ species adsorbed on activated sites are shown in Figure 1 (where DB is dangling bond). The periodic models of Si-terminated surface behave very similarly to C-terminated surface. The results indicate that the difference between $\mathrm{Si}$ - and $\mathrm{C}$ terminated surfaces is small in comparison. There are clearly some significant variations in the calculated reconstruction energies (and hence in the predicted minimum energy structures) that must be mentioned (Figure 1(c)). As can be seen by comparing the values for the various structural models, the maxima correspond to the $\mathrm{C}_{2} \mathrm{H}_{2}$ (II) species, and the difference is less than 0.1 hartree.

The computational results reveal that the silicon or carbon atom saturated by hydrogen atoms on the top layer surface is the most effective in increasing the stabilities of $\mathrm{CH}_{x}$ and $\mathrm{C}_{2} \mathrm{H}_{x}$ adsorption on the $\beta$-SiC (111) surface by comparing surface with dangling bond. This is in good agreement with earlier surface studies [25]. The associated values suggest that the $\mathrm{CH}_{3}$ radical molecule could form the most stable surface reconstruction among the $\mathrm{CH}_{x}$ adsorptions on the $\beta$-SiC (111) surface, which is consistent with the results of theoretical calculations [26]. The value of difference in Table 3 indicates that the hydrogen adsorption energy of $\mathrm{C}$ species adsorbed on the Si-terminated surface is a more attractive possibility than that of the $\mathrm{C}$ adsorption on the C-terminated surface. The difference in total energy between them has reached as high as $0.838 \mathrm{eV}$ per $(1 \times 1)$ unit

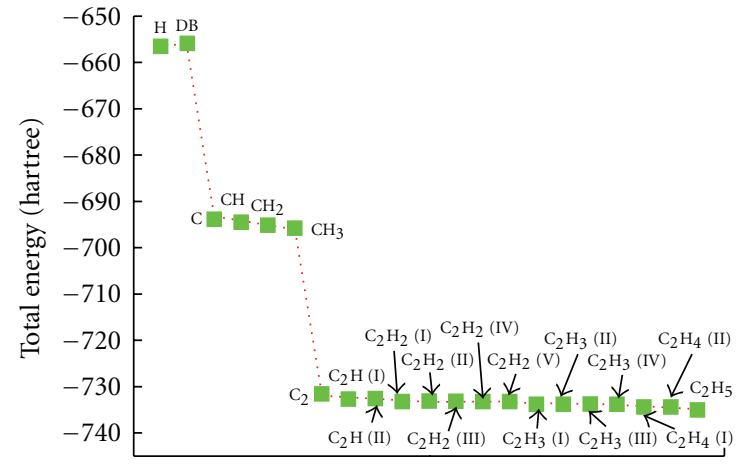

(a)

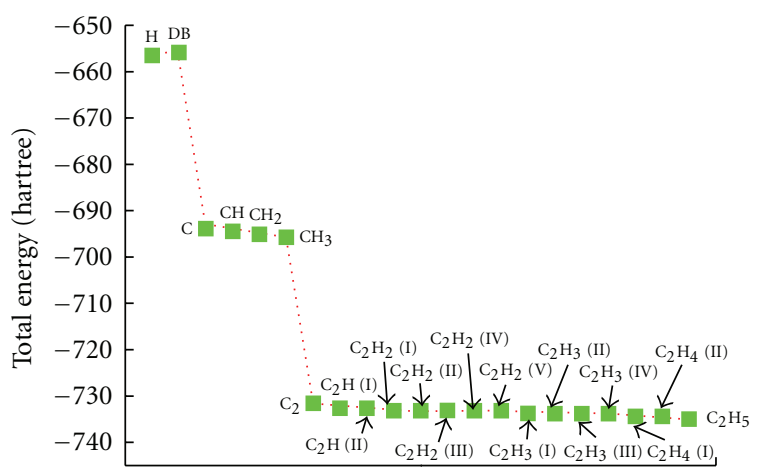

(b)

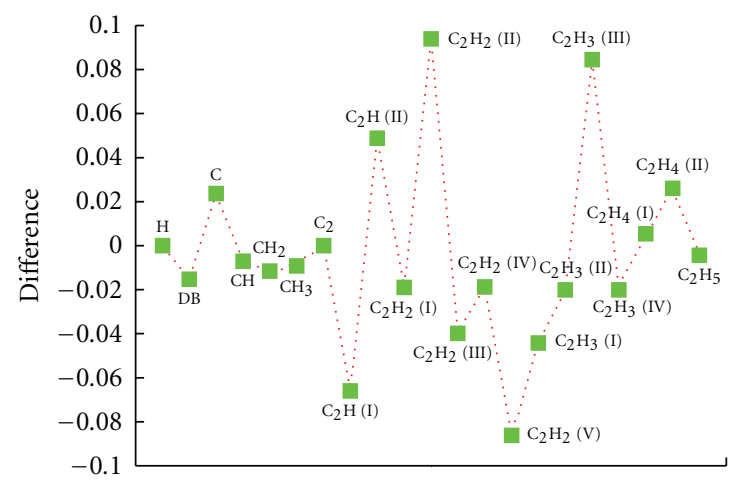

(c)

Figure 1: Total energies of $\mathrm{CH}_{x}$ and $\mathrm{C}_{2} \mathrm{H}_{x}$ adsorption on the $\beta$ $\mathrm{SiC}$ (111) surface. (a) Total energies of $\mathrm{CH}_{x}$ and $\mathrm{C}_{2} \mathrm{H}_{x}$ adsorption on the Si-terminated surface, (b) total energies of $\mathrm{CH}_{x}$ and $\mathrm{C}_{2} \mathrm{H}_{x}$ adsorption on the $\mathrm{C}$-terminated surface, and (c) the difference in total energies of $\mathrm{CH}_{x}$ and $\mathrm{C}_{2} \mathrm{H}_{x}$ adsorption between Si- and Cterminated surfaces.

cell. At the same time, the $\mathrm{CH}_{2}$ species has greater relevant step towards the formation of adsorbing the hydrogen by comparison with the $\mathrm{CH}$ species. The corresponding difference is 0.500 and $0.682 \mathrm{eV}$, respectively. These results agree with the previous theoretical studies very closely [27]. The calculated values of total energies suggest that the Siterminated surface is easier to adsorb the $\mathrm{CH}_{x}$ molecules than the C-terminated surface. 
TABLE 4: The difference in total energy between $\mathrm{C}_{2}$ adsorption and the other $\mathrm{C}_{2} \mathrm{H}_{x}$ adsorption on $\mathrm{Si}$ - and C-terminated surfaces.

\begin{tabular}{lcc}
\hline Species & Si-terminated surface $(\mathrm{eV})$ & $\mathrm{C}$-terminated surface $(\mathrm{eV})$ \\
\hline $\mathrm{C}_{2} \mathrm{H}(\mathrm{I})$ & -29.8228 & -28.0097 \\
$\mathrm{C}_{2} \mathrm{H}(\mathrm{II})$ & -26.6949 & -28.0061 \\
$\mathrm{C}_{2} \mathrm{H}_{2}(\mathrm{I})$ & -44.2762 & -43.7435 \\
$\mathrm{C}_{2} \mathrm{H}_{2}(\mathrm{II})$ & -41.2048 & -43.7434 \\
$\mathrm{C}_{2} \mathrm{H}_{2}(\mathrm{III})$ & -43.3547 & -42.253 \\
$\mathrm{C}_{2} \mathrm{H}_{2}(\mathrm{IV})$ & -44.2761 & -43.7485 \\
$\mathrm{C}_{2} \mathrm{H}_{2}(\mathrm{~V})$ & -44.974 & -42.6138 \\
$\mathrm{C}_{2} \mathrm{H}_{3}(\mathrm{I})$ & -60.3894 & -59.1696 \\
$\mathrm{C}_{2} \mathrm{H}_{3}(\mathrm{II})$ & -61.1584 & -60.5944 \\
$\mathrm{C}_{2} \mathrm{H}_{3}(\mathrm{III})$ & -58.3127 & -60.5957 \\
$\mathrm{C}_{2} \mathrm{H}_{3}(\mathrm{IV})$ & -61.158 & -60.5945 \\
$\mathrm{C}_{2} \mathrm{H}_{4}(\mathrm{I})$ & -76.5272 & -76.6586 \\
$\mathrm{C}_{2} \mathrm{H}_{4}(\mathrm{II})$ & -75.967 & -76.6585 \\
$\mathrm{C}_{2} \mathrm{H}_{5}$ & -93.4121 & -93.2752 \\
\hline
\end{tabular}

However, the $\mathrm{C}_{2} \mathrm{H}_{x}$ species is complex as various prototypes can exist under certain conditions, including $\mathrm{C}-\mathrm{C}$ and $\mathrm{C}=\mathrm{C}$ bond. In this paper, all of the $\mathrm{C}_{2} \mathrm{H}_{x}$ allotropes are studied in theory by DFT method to obtain the structural properties (see Table 4). Our results reveal that the $\mathrm{C}_{2} \mathrm{H}$ (I) adsorption on the Si-terminated surface is slightly favored with respect to the $\mathrm{C}$-terminated surface. Interestingly, total energies of $\mathrm{C}_{2} \mathrm{H}$ (I) and $\mathrm{C}_{2} \mathrm{H}$ (II) species adsorbed on C-terminated surface remain slightly the same, which indicates that the relative position of the intramolecular hydrogen bond has small influences on the stability of the surface reconstruction. The calculated results based on the analysis of total energies suggest that these two surface reconstructions will occur at the same time during the CVD diamond formation. Figure 2(a) shows the optimized structure model for $\mathrm{C}_{2} \mathrm{H}$ (II) adsorption, where the adsorbed molecule has a $\mathrm{C}-\mathrm{H}$ bond length of $2.27 \AA$. As far as the energetics and the geometries are concerned, we confirm that the $\mathrm{C}_{2} \mathrm{H}$ (II) adsorption on C-terminated surface cannot present in the process of CVD diamond film growth.

Five allotropes of $\mathrm{C}_{2} \mathrm{H}_{2}$ species are investigated in this paper. As can be seen the $\mathrm{C}_{2} \mathrm{H}_{2}$ (I) adsorption holds the most stability of surface reconstruction among the five allotropes. By comparison of the total energies of $\mathrm{C}_{2} \mathrm{H}_{2}$ (I) and $\mathrm{C}_{2} \mathrm{H}_{2}$ (II) adsorption, it is no surprise to find that these two surface reconstructions have the same probability occurring during diamond formation, while the $\mathrm{C}-\mathrm{H}$ bond length of $2.10 \AA$ indicates that the $\mathrm{C}_{2} \mathrm{H}_{2}$ (II) adsorption does not occur in practical CVD diamond coating (see Figure 2(b)). Interestingly, the geometry optimization shows that the $\mathrm{C}_{2} \mathrm{H}_{2}$ (II) adsorption can terminally migrate to $\mathrm{C}_{2} \mathrm{H}_{2}$ (I) adsorption. Consequently, $\mathrm{C}_{2} \mathrm{H}_{2}$ (I) species is energetically more favorable for fabricating CVD diamond coatings than $\mathrm{C}_{2} \mathrm{H}_{2}$ (II) species. Due to the large total energy, the $\mathrm{C}_{2} \mathrm{H}_{2}$ (II) adsorption is hard to form the surface reconstruction in situ.

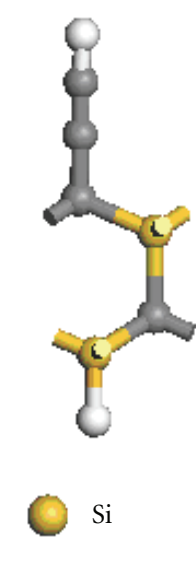

(a)

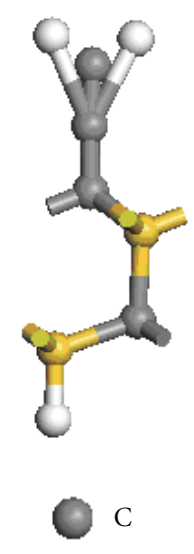

(b)

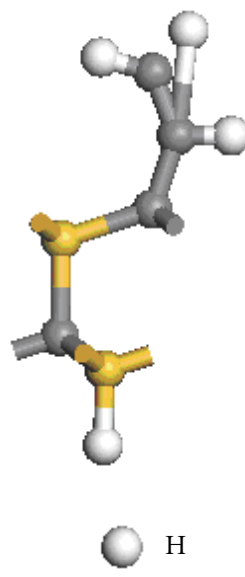

(c)
Figure 2: The optimizing geometry of $\mathrm{C}_{2} \mathrm{H}_{x}$ adsorption on the C-terminated surface: (a) the $\mathrm{CH}-\mathrm{C}$ adsorption, (b) the $\mathrm{CH}_{2}-\mathrm{C}$ adsorption, and (c) the $\mathrm{CH}_{2}-\mathrm{CH}$ adsorption.

For $\mathrm{C}_{2} \mathrm{H}_{2}(\mathrm{IV})$ and $\mathrm{C}_{2} \mathrm{H}_{2}(\mathrm{~V})$ species with a $\mathrm{C}=\mathrm{C}$ bond, the $\mathrm{C}_{2} \mathrm{H}_{2}$ (IV) adsorption on the C-terminated surface is slightly favored with respect to $\mathrm{C}_{2} \mathrm{H}_{2}(\mathrm{~V})$ adsorption. Conversely, the $\mathrm{C}_{2} \mathrm{H}_{2}(\mathrm{~V})$ adsorption on the Si-terminated surface is found to be the most effective in the stability of surface reconstruction. In addition, from the calculated adsorption energies, the species with a $\mathrm{C}=\mathrm{C}$ bond are energetically more favorable for fabricating $\mathrm{CVD}$ diamond coatings than those with a $\mathrm{C}-\mathrm{C}$ bond. This conclusion is evident by looking at the result of kinetic Monte Carlo (KMC) simulations [1].

Similarly, the $\mathrm{C}_{2} \mathrm{H}_{3}$ adsorption on the $\beta$-SiC (111) surface has four surface reconstructions. For the Si-terminated surface, the calculated results reveal that the $\mathrm{C}_{2} \mathrm{H}_{3}$ (II) and $\mathrm{C}_{2} \mathrm{H}_{3}$ (IV) adsorption has the most favorable stability of surface reconstructions. It is worth noting that more hydrogen atoms saturating the top layer species, such as C$\mathrm{CH}_{3}$ adsorption, will result in more stability of the surface reconstructions. Additionally, the simulations also find very similar values for $\mathrm{Si}_{d}-\mathrm{CH}-\mathrm{CH}_{2}$ and $\mathrm{Si}_{d}-\mathrm{CH}=\mathrm{CH}_{2}$ surface reconstructions. This is consistent with the adsorbing activity of $\mathrm{Si}_{d}-\mathrm{C}-\mathrm{CH} 2$ and $\mathrm{Si}_{d}-\mathrm{C}=\mathrm{CH}_{2}$ surface reconstructions, while this state differs significantly for both $\mathrm{Si}_{d}-\mathrm{CH}-\mathrm{CH}$ surface reconstruction and $\mathrm{Si}_{d}-\mathrm{CH}=\mathrm{CH}$ surface reconstruction. Obviously, the carbon-carbon single or double bonds do not play a valid role in determining the stability of surface reconstructions. For the C-terminated surface, $\mathrm{C}_{2} \mathrm{H}_{3}$ (III) adsorption holds the most stability of surface reconstruction. From the calculated geometry, the length of $\mathrm{C}-\mathrm{H}$ bond is $2.08 \AA$ (see Figure $2(\mathrm{c})$ ), which suggests that $\mathrm{C}_{2} \mathrm{H}_{3}$ (III) adsorption does not exit during CVD diamond formation. Therefore, $\mathrm{C}_{2} \mathrm{H}_{3}$ (II) species and $\mathrm{C}_{2} \mathrm{H}_{3}$ (IV) species are considered as the most stability of surface reconstruction among the $\mathrm{C}_{2} \mathrm{H}_{3}$ adsorption on the C-terminated surface. Thus, the $\mathrm{C}_{2} \mathrm{H}_{3}$ (II) and $\mathrm{C}_{2} \mathrm{H}_{3}$ (IV) adsorption can present at the same time during the diamond film growth. 
For the $\mathrm{C}_{2} \mathrm{H}_{4}$ adsorption, two surface reconstructions are investigated. The calculated results find that $\mathrm{C}_{2} \mathrm{H}_{4}$ (I) adsorption on the Si-terminated surface has more stability than that of the $\mathrm{C}_{2} \mathrm{H}_{4}$ (II), while the $\mathrm{C}_{2} \mathrm{H}_{4}$ (I) adsorption on the $\mathrm{C}$-terminated surface has the same probability with respect to $\mathrm{C}_{2} \mathrm{H}_{4}$ (II) adsorption. $\mathrm{C}_{2} \mathrm{H}_{5}$ adsorption on the $\beta$ $\mathrm{SiC}$ (111) surface has only one surface reconstruction, where both two carbon atoms are saturated by hydrogen atoms.

Therefore, from the energetics and the geometry, we find that the position of hydrogen atoms on the $\mathrm{C}_{2} \mathrm{H}_{x}$ species is the most effective among the stabilities of surface reconstructions. For the C-terminated surface, the surface reconstruction with the saturated carbon atoms on the top layer species is slightly favorable stability with respect to those with dangling bond. However, for the Si-terminated surface, the saturated carbon atom on the sublayer species is useful for the stability of surface reconstructions. Meanwhile, $\mathrm{C}-\mathrm{CH}$ adsorption on $\mathrm{Si}$ - or C-terminated surface has more stability than the $\mathrm{C}-\mathrm{C}$ adsorption with fully dangling bond. In addition, $\mathrm{C}_{2} \mathrm{H}_{5}$ adsorption on the $\mathrm{C}$-terminated surface can be formed concurrently at different surface locations through many instances of reactions, such as adsorbing one hydrogen atoms on $\mathrm{C}_{2} \mathrm{H}_{4}$ species. The calculated values indicate that the $\mathrm{C}_{2} \mathrm{H}_{4}$ species has larger hydrogen adsorption energy than the others. Therefore, $\mathrm{C}_{2} \mathrm{H}_{5}$ adsorption has the most favorable stability of surface reconstruction. For the Si-terminated surface, the $\mathrm{CH}-\mathrm{CH}_{2}$ and $\mathrm{CH}=\mathrm{CH}_{2}$ species hold the highest hydrogen adsorption energy, which make these two species more stable. Interestingly, the Si- and C-terminated surfaces do not present the similar properties of adsorbing the $\mathrm{CH}_{x}$ and $\mathrm{C}_{2} \mathrm{H}_{x}$ molecules. The calculated results demonstrate that the Si-terminated surface is much easier to deposit the diamond film than the C-terminated surface.

\section{Conclusions}

In this paper, the $\mathrm{CH}_{x}$ and $\mathrm{C}_{2} \mathrm{H}_{x}$ adsorption on the $\beta$-SiC (111) surface has been investigated to highlight specific insight into the initial-stage growth of diamond film on SiC substrates. The geometry optimization and energies of all the surface reconstructions have been calculated by the DFT method. The calculation of the energetics and the geometry shows that $\mathrm{C}_{2} \mathrm{H}_{x}$ adsorption on the Si-terminated surfaces has six possible surface reconstructions, including $\mathrm{C}-\mathrm{CH}$, $\mathrm{CH}=\mathrm{CH}, \mathrm{CH}-\mathrm{CH}_{2}, \mathrm{CH}=\mathrm{CH}_{2}, \mathrm{CH}-\mathrm{CH}_{3}$, and $\mathrm{CH}_{2}-\mathrm{CH}_{3}$ species. The $\mathrm{CH}-\mathrm{CH}_{2}$ and $\mathrm{CH}=\mathrm{CH}_{2}$ species hold the largest hydrogen adsorption energy. For the C-terminated surface, there exist eight possible surface reconstructions which include $\mathrm{C}-\mathrm{CH}, \mathrm{C}-\mathrm{CH}_{2}, \mathrm{C}=\mathrm{CH}_{2}, \mathrm{CH}-\mathrm{CH}_{2}, \mathrm{CH}=\mathrm{CH}_{2}$, $\mathrm{CH}-\mathrm{CH}_{3}, \mathrm{CH}_{2}-\mathrm{CH}_{2}$, and $\mathrm{CH}_{2}-\mathrm{CH}_{3}$ species. The hydrogen adsorption energies indicate that $\mathrm{C}_{2} \mathrm{H}_{5}$ adsorption has the most stability of surface reconstruction. Meanwhile, the $\mathrm{CH}_{2}$ adsorption on the Si- or C-terminated surface also has the largest hydrogen adsorption energy. Calculations also indicate that position of hydrogen atoms on the $\mathrm{C}_{2} \mathrm{H}_{x}$ species is related to the stabilities of surface reconstructions. The calculated results demonstrate that the Si-terminated surface is energetically more favorable for fabricating CVD diamond coatings than the C-terminated surface.

\section{Acknowledgments}

This paper is sponsored by the National Natural Science Foundation of China (no. 50975177), the National Hightech R\&D Program (863 Program) of China in the Field of Advanced Manufacturing (2009AA044304-1), the Shanghai Science and Technology Plan of Action for Technical Standards for Innovation and Special (08DZ0501700), and the Shanghai Science and Technology Plan of Action for Nano Science and Technology for Innovation and Special (0952nm01700).

\section{References}

[1] A. Netto and M. Frenklach, "Kinetic Monte Carlo simulations of CVD diamond growth-Interlay among growth, etching, and migration," Diamond and Related Materials, vol. 14, no. 10, pp. 1630-1646, 2005.

[2] D. E. Kassmann and T. A. Badgwell, "Analysis of process modifications for efficient diamond chemical vapor deposition," Diamond and Related Materials, vol. 5, no. 9, pp. 895-906, 1996.

[3] M. E. Coltrin and D. S. Dandy, "Analysis of diamond growth in subatmospheric dc plasma-gun reactors," Journal of Applied Physics, vol. 74, no. 9, pp. 5803-5820, 1993.

[4] J. C. Arnault, S. Saada, S. Delclos et al., "In situ study of the initial stages of diamond deposition on 3C-SiC (100) surfaces: towards the mechanisms of diamond nucleation," Diamond and Related Materials, vol. 16, no. 4-7, pp. 690-694, 2007.

[5] S. Chowdhury, E. de Barra, and M. T. Laugier, "Study of mechanical properties of CVD diamond on SiC substrates," Diamond and Related Materials, vol. 13, no. 9, pp. 1625-1631, 2004.

[6] M. Frenklach and H. Wang, "Detailed surface and gas-phase chemical kinetics of diamond deposition," Physical Review B, vol. 43, no. 2, pp. 1520-1545, 1991.

[7] D. E. Kassmann and T. A. Badgwell, "Modeling diamond chemical vapor deposition in a rotating disk reactor," Diamond and Related Materials, vol. 5, no. 3-5, pp. 221-225, 1996.

[8] X. An, G. Liu, F. Wang, and S. Liu, "Electronic structure study of growth species adsorption and reaction on cluster models for the diamond surface using LDA method," Diamond and Related Materials, vol. 12, no. 12, pp. 2169-2174, 2003.

[9] S. Chowdhury, E. de Barra, and M. T. Laugier, "Hardness measurement of CVD diamond coatings on SiC substrates," Surface and Coatings Technology, vol. 193, no. 1-3, pp. 200205, 2005.

[10] S. Chowdhury, M. T. Laugier, and J. Henry, "XRD stress analysis of CVD diamond coatings on SiC substrates," International Journal of Refractory Metals and Hard Materials, vol. 25, no. 1, pp. 39-45, 2007.

[11] B. Stankiewicz and L. Jurczyszyn, "Computations of STM images of $\operatorname{SiC}\left(\begin{array}{lll}0 & 0 & 1\end{array}\right)-\mathrm{c}(2 \times 2)$ surface," Surface Science, vol. 507-510, pp. 463-467, 2002.

[12] W. Lu, P. Krüger, and J. Pollmann, "Atomic and electronic structure of $\beta$-SiC(001)- $(3 \times 2)$," Physical Review B, vol. 60, no. 4, pp. 2495-2504, 1999.

[13] A. M. Mazzone, "Acetylene adsorption on Si(1 0 0): a study of the role of surface steps," Surface Science, vol. 601, no. 1, pp. 218-226, 2007.

[14] W. Lu, P. Krüger, and J. Pollmann, "Ab initio studies on the $\beta$ SiC(001)-(5 × 2) surface," Physical Review B, vol. 61, no. 4, pp. 2680-2687, 2000. 
[15] C. Koitzsch, D. Conrad, K. Scheerschmidt, and U. Gösele, "Empirical molecular dynamic study of $\mathrm{SiC}(0001)$ surface reconstructions and bonded interfaces," Journal of Applied Physics, vol. 88, no. 12, pp. 7104-7109, 2000.

[16] M. Schaible, "Empirical molecular dynamics modeling of silicon and silicon dioxide: a review," Critical Reviews in Solid State and Materials Sciences, vol. 24, no. 4, pp. 265-323, 1999.

[17] A. J. Dyson and P. V. Smith, "Empirical potential study of the chemisorption of $\mathrm{C}_{2} \mathrm{H}_{2}$ and $\mathrm{CH}_{3}$ on the $\beta$-SiC $(001)$ surface," Surface Science, vol. 396, no. 1-3, pp. 24-39, 1998.

[18] J. Wieferink, P. Krüger, and J. Pollmann, "First-principles study of acetylene adsorption on $\beta$-SiC $(001)-(3 \times 2)$," Physical Review B, vol. 75, no. 15, Article ID 153305, 2007.

[19] J. Wieferink, P. Krüger, and J. Pollmann, "First-principles study of acetylene and ethylene adsorption on $\beta$-SiC(001)-(2 $\times$ 1), Physical Review B, vol. 73, no. 11, Article ID 115309, 12 pages, 2006.

[20] J. Pollmann, P. Krüger, and M. Sabisch, "Atomic and electronic structure of SiC surfaces from ab-initio calculations," Physica Status Solidi B, vol. 202, no. 1, pp. 421-445, 1997.

[21] B. Delley, "An all-electron numerical method for solving the local density functional for polyatomic molecules," The Journal of Chemical Physics, vol. 92, no. 1, pp. 508-517, 1990.

[22] B. Delley, "Fast calculation of electrostatics in crystals and large molecules," Journal of Physical Chemistry, vol. 100, no. 15, pp. 6107-6110, 1996.

[23] B. Delley, "From molecules to solids with the $\mathrm{DMol}^{3}$ approach," Journal of Chemical Physics, vol. 113, no. 18, pp. 7756-7764, 2000.

[24] H. J. Monkhorst and J. D. Pack, "Special points for Brillouinzone integrations," Physical Review B, vol. 13, no. 12, pp. 5188$5192,1976$.

[25] S. J. Harris, "Mechanism for diamond growth from methyl radicals," Applied Physics Letters, vol. 56, no. 23, pp. 2298 2300, 1990.

[26] A. J. Dyson and P. V. Smith, "A molecular dynamics study of the chemisorption of $\mathrm{C}_{2} \mathrm{H}_{2}$ and $\mathrm{CH}_{3}$ on the $\mathrm{Si}(001)-(2 \times 1)$ surface," Surface Science, vol. 375, no. 1, pp. 45-54, 1997.

[27] Y. A. Mankelevich and P. W. May, "New insights into the mechanism of CVD diamond growth: single crystal diamond in MW PECVD reactors," Diamond and Related Materials, vol. 17, no. 7-10, pp. 1021-1028, 2008. 

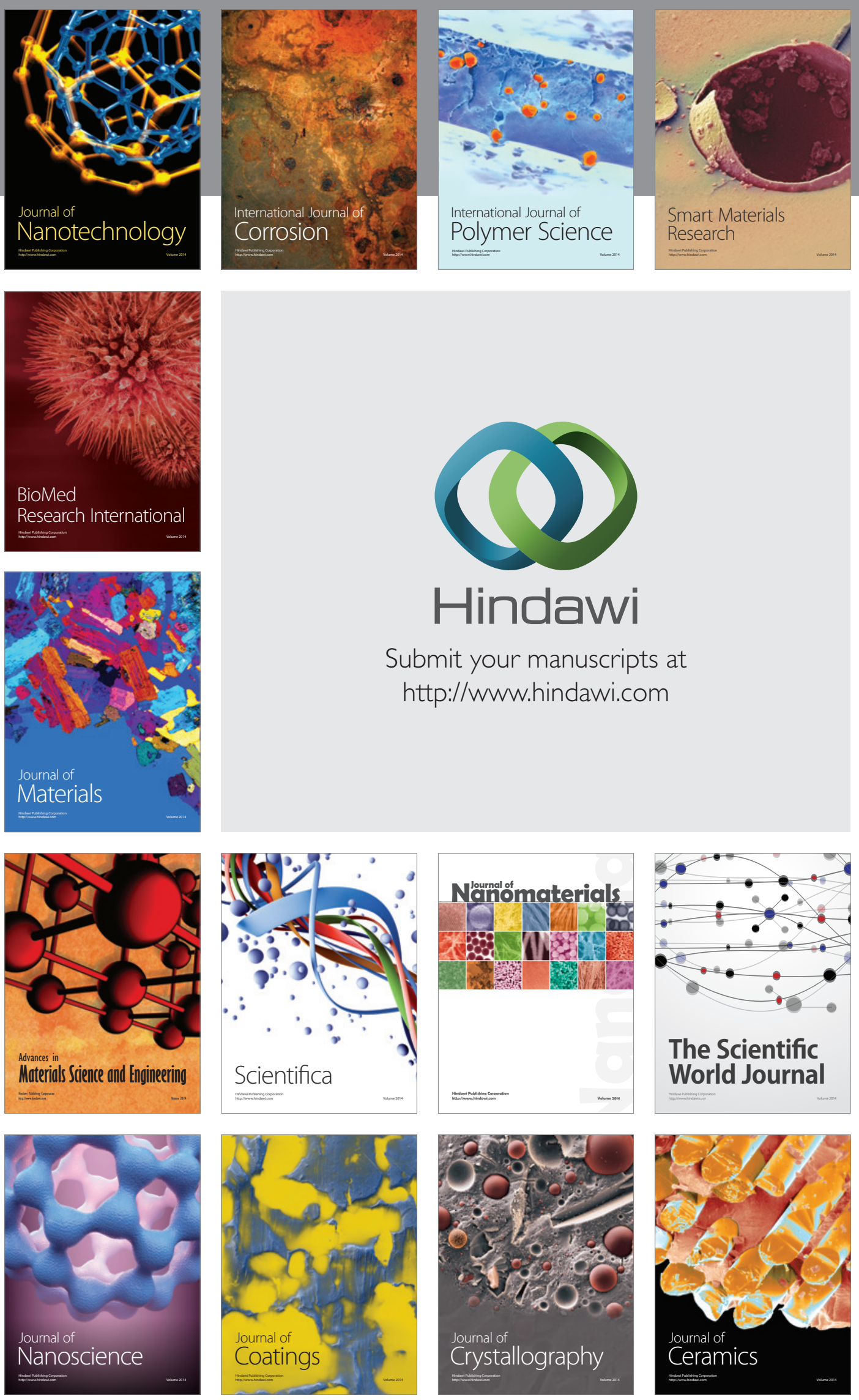

The Scientific World Journal

Submit your manuscripts at

http://www.hindawi.com

\section{World Journal}

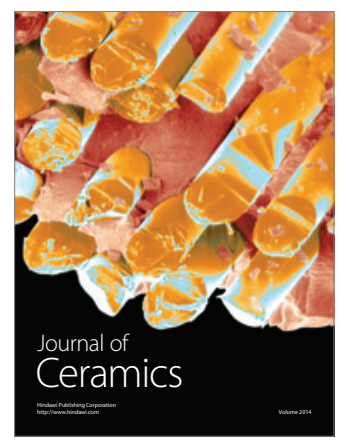

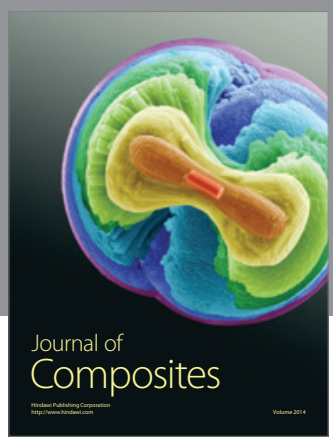
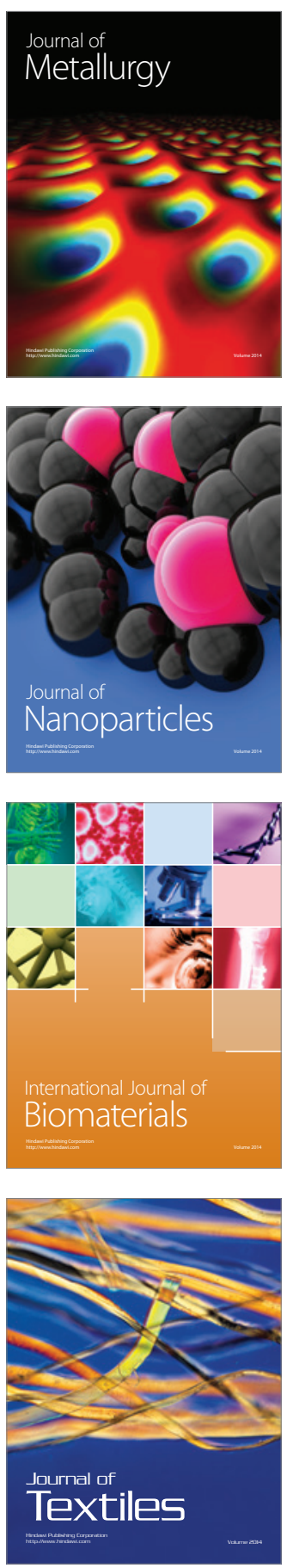